\title{
Theoretical Studies Unveil the Unusual Bonding in Oxygenation Reactions Involving Cobalt(II)-lodylarene Complexes \\ DOI:
}

10.1039/DOCC07894H

\section{Document Version}

Accepted author manuscript

Link to publication record in Manchester Research Explorer

Citation for published version (APA):

Chen, X., Sun, D., Gao, L., Yufen, Z., De Visser, S., \& Wang, Y. (2021). Theoretical Studies Unveil the Unusual Bonding in Oxygenation Reactions Involving Cobalt(II)-Iodylarene Complexes. Chemical Communications. https://doi.org/10.1039/D0CC07894H

\section{Published in:}

Chemical Communications

\section{Citing this paper}

Please note that where the full-text provided on Manchester Research Explorer is the Author Accepted Manuscript or Proof version this may differ from the final Published version. If citing, it is advised that you check and use the publisher's definitive version.

\section{General rights}

Copyright and moral rights for the publications made accessible in the Research Explorer are retained by the authors and/or other copyright owners and it is a condition of accessing publications that users recognise and abide by the legal requirements associated with these rights.

\section{Takedown policy}

If you believe that this document breaches copyright please refer to the University of Manchester's Takedown Procedures [http://man.ac.uk/04Y6Bo] or contact uml.scholarlycommunications@manchester.ac.uk providing relevant details, so we can investigate your claim.

\section{OPEN ACCESS}




\section{Theoretical Studies Unveil the Unusual Bonding in Oxygenation Reactions Involving Cobalt(II)-lodylarene Complexes}

Received 00th January 20xx, Accepted 00th January 20xx DOI: $10.1039 / x 0 x \times 00000 x$

\author{
Xiaolu Chen, ${ }^{a, b}$ Dongru Sun, ${ }^{* a, b}$ Lanping Gao, ${ }^{a, b}$ Yufen Zhao ${ }^{a, b}$ Sam P. de Visser*c and Yong \\ Wang*a,b
}

DFT calculations reveal that the iodine of cobalt(II)-iodylarene complexes acts as a directing group via halogen bonding interaction to substrates. A transient $3 \mathrm{c}-4 \mathrm{e}$ bond is formed during oxidation reactions to decrease the activation energy by electron delocalization. Dihydrogenation of dihydroantharacene proceeds via a novel concerted hydride transfer/proton transfer mechanism.

Due to the advantages of environmentally benign hypervalent iodine complexes, especially ones containing iodine(III) and iodine $(\mathrm{V})$, they are widely employed in biomimetic oxidation, as well as in organic and drug synthesis. ${ }^{1-2}$ The commonly used iodosylbenzene $\left((\mathrm{PhIO})_{n}\right.$, Scheme 1a), is a polymer insoluble in most organic solvents. Addition of acids, halogens or metal salts; however, make them soluble in organic solvents, such as acetonitrile, and enable to utilize them in oxidation reactions, by reacting it into stable iodine(III) complexes (examples see Scheme 1a). ${ }^{2}$ Among these iodine(III) complexes, metaliodosylarenes (M-PhIO) are commonly used as the precursor to generate high-valent metal-oxo oxidants. ${ }^{3}$ Recently, a debate on the one-oxidant versus the multiple-oxidant mechanism in $\mathrm{M}-\mathrm{PhlO}$ chemistry was triggered as a hot issue in biomimetic chemistry. In particular, several studies implicated oxidative activity by the M-PhIO intermediate. ${ }^{4-7}$

Similarly to iodosylbenzene, the iodylbenzene $\left(\left(\mathrm{PhIO}_{2}\right)_{n}\right.$, Scheme $1 \mathrm{~b})$, is also an insoluble polymer in most solvents and can be used to generate high-valent oxidants. ${ }^{1}$ Introducing substituents on the phenyl ring of $\mathrm{PhIO}_{2}$ enables the formation of an intramolecular halogen bond to make the complexes hold

a. Institute of Drug Discovery Technology, Ningbo University, Ningbo, Zhejiang, China

Email: sundongru@nbu.edu.cn,yong@nbu.edu.cn

b. Qian Xuesen Collaborative Research Center of Astrochemistry and Space Life Sciences, Ningbo University, Ningbo, Zhejiang, China

Manchester Institute of Biotechnology and Department of Chemical Engineering and Analytical Science, The University of Manchester, 131 Princess Street, Manchester M1 7DN, United Kingdom

Email:sam.devisser@manchester.ac.uk

+ Electronic Supplementary Information (ESI) available: details of the computational methodology, energies, geometric and electronic structures, and Cartesian coordinates of all reaction intermediates. See DOI: 10.1039/x0xx00000x a)<smiles>Oc1cccc2ccccc12</smiles>

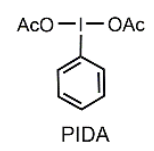<smiles>Oc1ccc(C(Cl)Cl)cc1</smiles><smiles>COc1ccccc1OCO</smiles>

b)

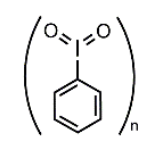<smiles>O=P(O)(O[Na])c1ccccc1S(=O)(=O)O</smiles><smiles>O=C1OP2(=O)OCC12O</smiles>

IBX

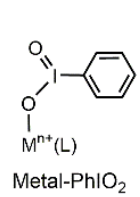

c) $\left(\mathrm{PhIO}_{2}\right)_{\mathrm{n}}$$$
\text { O }
$$<smiles>O=[IH](O)[Al]</smiles>


Scheme 1. Some representative (a) iodine (III) and (b) iodine(V) complexes, and
(c) a proposed multiple-oxidant reaction mechanism for oxygenation mediated by (c) a proposed multiple-oxid
metal-iodyarene complexes.

in a pseudocyclic (e.g. ${ }^{\mathrm{S}} \mathrm{PhIO}_{2}$ ) or a cyclic form (e.g. 2iodylbenzoic acid (IBX)) that increases their solubility. ${ }^{2}$ Introduction of metal complexes can convert them to metaliodylarene adducts $\left(\mathrm{M}-\mathrm{PhIO}_{2}\right)$ that are more reactive. ${ }^{8-9}$ As such, developments into the design of suspected new biomimetic $\mathrm{M}$ $\mathrm{PhIO}_{2}$ catalysts are actively ongoing. ${ }^{10-12}$

Barret and co-workers reported that by the combination of iodylbenzene and vanadium catalysts, aromatic amines were readily converted into quinone-imines under mild conditions. ${ }^{8}$ It was subsequently found by Zhdankin and co-workers that addition of $\mathrm{Fe}$ (III)-phthalocyanine to the IBX system led to the conversion of alcohols to their oxidized products, while a Co(II)porphyrin complex did not show any significant activity. ${ }^{9-10}$ They attributed this catalyst selectivity to the formation of an iron(IV)-oxo species from the $\mathrm{M}-\mathrm{PhIO}_{2}$ precursors (Scheme 1c). ${ }^{10}$ Besides of a rate-limiting formation step of high valent metal-oxo intermediates, there is also a possibility that the metal-iodylarene adducts are directly involved in the oxidation or alter the reaction rates. Subsequently, Leung and co-workers reported the first X-ray structure of a lanthanide $\mathrm{Ce}(\mathrm{IV})-\mathrm{PhIO}_{2}$ 
complex which exhibit robust reactivity in organic oxidation. ${ }^{11}$ Very recently, a cobalt-iodylarene complex, namely $\left[\mathrm{Co}(\mathrm{II}) \mathrm{Tp}^{\mathrm{tBu}}\left(\mathrm{sPhIO}_{2}\right)\right]^{+}\left(\mathrm{Tp}=\right.$ hydrotris (pyrazolyl) borate and ${ }^{\mathrm{S} P h}=$ 2-(tert-butylsulfonyl) phenyl) (1), was synthesized and crystallized by Anderson and his co-workers. The complex showed oxidative activity through sulfoxidation of thioanisole and dehydrogenation of 9,10-dihydroanthracene (DHA). ${ }^{12}$ Further mechanistic studies supported a mechanism that the Co-PhIO ${ }_{2}$ adduct, not the high-valent cobalt-oxo complex (Scheme 1c), is the most likely oxidant in the reactions although no technical details could be determined. ${ }^{12}$ In particular, no cobalt(IV)-oxo intermediate could be trapped and characterized and kinetic isotope effects studies were inconclusive whether a potential cobalt(IV)-oxo species was involved in the reaction mechanism.

As little is known on the details of the mechanism and whether either a Co(IV)-oxo or a Co- $\mathrm{PhIO}_{2}$ species is involved in the substrate activation, we decided to perform a comprehensive computational study of the elusive structureactivity relationship of $\mathbf{1}$. Our results are consistent with the experimental observation that $\mathbf{1}$ is directly involved in reactivity. We also obtain some interesting mechanistic findings, namely that the metal-iodylarene $\left(\mathrm{M}-\mathrm{PhIO}_{2}\right)$ chemistry is quite different

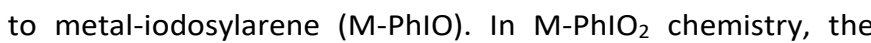
iodine of metal-iodylarene complexes acts as a directing group via halogen bonding interaction to substrates. A transient three center-four electron bond ( $3 c-4 e$ bond) is formed in the transient T-shaped (metal)-O-I-O-(substrate) moiety of $\mathbf{1}$ during substrates approach, which decreases the activation energy by electron delocalization. To the best of our knowledge, these two mechanistic properties have not been reported in M-PhIO chemistry.

For 1 , the calculated ground state is the quartet spin state $(S$ $=3 / 2$ ), which is consistent with experimental observation. ${ }^{12}$ Since the excited doublet/sextet states are higher in energy than ${ }^{4} 1$ by $20.9 / 26.9 \mathrm{kcal} \mathrm{mol}^{-1}$, we will focus in the main text on the quartet spin state data only. For ${ }^{4} \mathbf{1}$ (Fig. 1a), key distances calculated are: Co-O1 at $1.971 \AA$ A, I-O1 of $1.851 \AA$ and I-O2 of $1.788 \AA$. The $1-\mathrm{O}\left(\mathrm{SO}_{2}\right)$ distance of the intramolecular halogen bond is $2.544 \AA$, while the angle of the O1-1-02 moiety is $106.2^{\circ}$. Overall, the calculated geometry of 1 fits the experimental crystal structure well. ${ }^{12}$ Cleavage of the I-O1 bond generates a

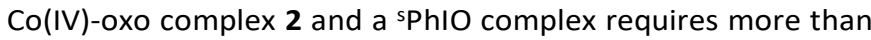
$40.0 \mathrm{kcal} \mathrm{mol}^{-1}$ in activation energy for 1 (Fig. S2, ESI). Therefore, this conversion is kinetically unfeasible and the active species is the Co-PhIO 2 species 1 , not the high-valent cobalt(IV)-oxo species.

The reactivity of $\mathbf{1}$ in thioanisole sulfoxidation is presented in Fig. 2. For the reagent complex state $\left({ }^{4} R C\right)$, there are two halogen bonds (abbreviated to $\mathrm{XB}$ ): one is the intramolecular I$\mathrm{O}$ (sulfonyl) XB bond retained from ${ }^{\mathrm{S}} \mathrm{PhIO}_{2}$, with a distance of $2.567 \AA$ (Fig. S4, ESI), while the other is the intermolecular I$\mathrm{S}$ (thioanisole) XB bond, with a distance of $3.114 \AA$ A. The iodine of 1 reserves a vacant position for binding of an electron-rich group of the substrate via a halogen bond. Thus, the iodine(V) core acts as a directing group during substrate binding. A reactant complex without such XB interaction (Fig. S8, ESI) lies a)

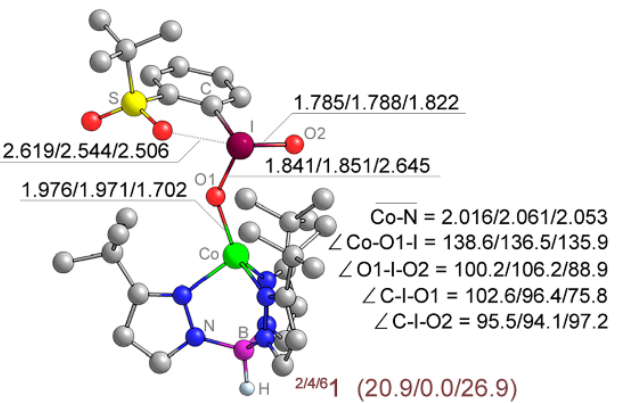

b)

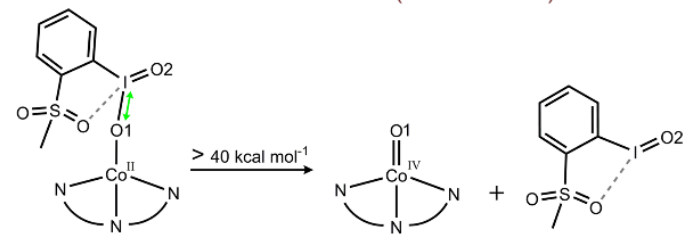

Fig. 1 (a) Key energetic and geometric information of $\mathbf{1}$ on the moiety) are omitted for clarity. Hydrogen atoms (expect hydrogen of the and energies are in kcal mol-1 units. (b) Schematic plot of the conversion of 1 to the high-valent $\mathrm{Co}(\mathrm{IV})$-oxo species $\mathbf{2}$. The dotted-lines denote halogen bonding.

$5.2 \mathrm{kcal} \mathrm{mol}^{-1}$ higher in energy than this RC. Such XB interaction anchors the substrate cis to the oxygen atom of $\mathbf{1}$, with a distance of $3.383 \AA$ A. The sulfoxidation process proceeds via a direct oxygen-atom transfer mechanism, with an activation

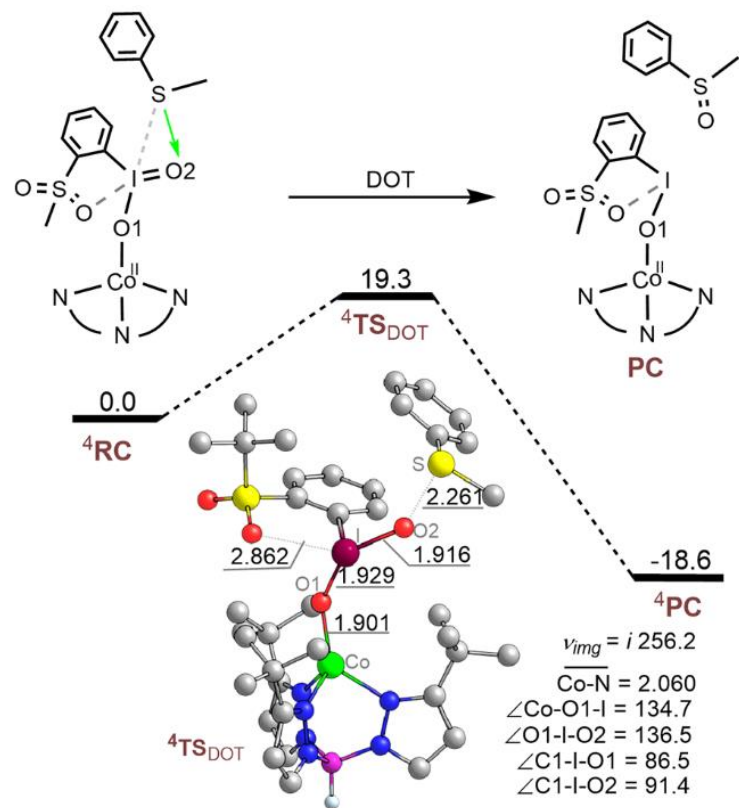

Fig. 2 The energy profile (in $\mathrm{kcal} \mathrm{mol}^{-1}$ ) for sulfoxidation of thioanisole by $\mathbf{1}$ via a direct oxygen-atom transfer (DOT) mechanism. Energies were calculated at the UB3LYP-D3(BJ)/B2//B1+ZPE/B1 level in solvent. Geometric information of the transition state is presented. Hydrogen atoms (expect hydrogen of the $\mathrm{H}-\mathrm{B}$ moiety) are omitted for clarity. Lengths are in A units, angles are in degree units, and the imaginary frequency is in $\mathrm{cm}^{-1}$ units. The dotted-lines denote halogen bonding.

energy of $19.3 \mathrm{kcal} \mathrm{mol}^{-1}$. For the transition state $\left({ }^{4} \mathrm{TS}\right)$, there are significant geometric changes in the cobalt-iodylarene moiety (Fig. S4, ESI), i.e., the O1-I-O2 angle increases dramatically from $102.9^{\circ}$ for ${ }^{4} \mathrm{RC}$ to $136.5^{\circ}$ for ${ }^{4} \mathrm{TS}$, forming an approximate $\mathrm{T}$ shaped $\mathrm{O} 1-\mathrm{I}(\mathrm{Ph})-\mathrm{O} 2$ species. This growth of angle extends until the product complex $\left({ }^{4} \mathrm{PC}\right)$ is reached, where the 01-I-O2 angle is ca. $170.9^{\circ}$ (Fig. S4 and S5, ESI). Comparison of the three representative Pmentel-Rundle molecular orbitals ${ }^{13}$ (the anti-, 
a)



$\infty \infty \Psi_{\text {anti-bonding }}^{\Psi_{3}}$

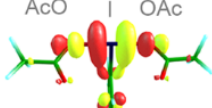

$\infty$-.-.-

$\infty \infty$ ft $\begin{aligned} & \Psi_{1} \\ & \text { bonding }\end{aligned}$

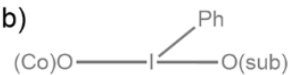

$\infty \infty \Psi_{\text {anti-bonding }}^{\Psi_{3}}$

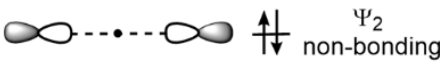

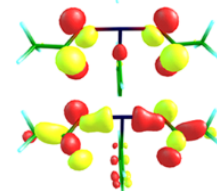

(1)

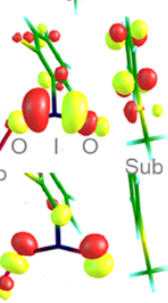

$\infty \infty \infty$ it $\begin{gathered}\Psi_{1} \\ \text { bonding }\end{gathered}$

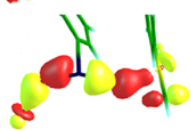

Fig. 3 The representative Pmentel-Rundle MO depiction of $3 c-4 e$ bonds (a) in PIDA Fig.
and (b) in the transition state of thioanisole oxidation by 1.

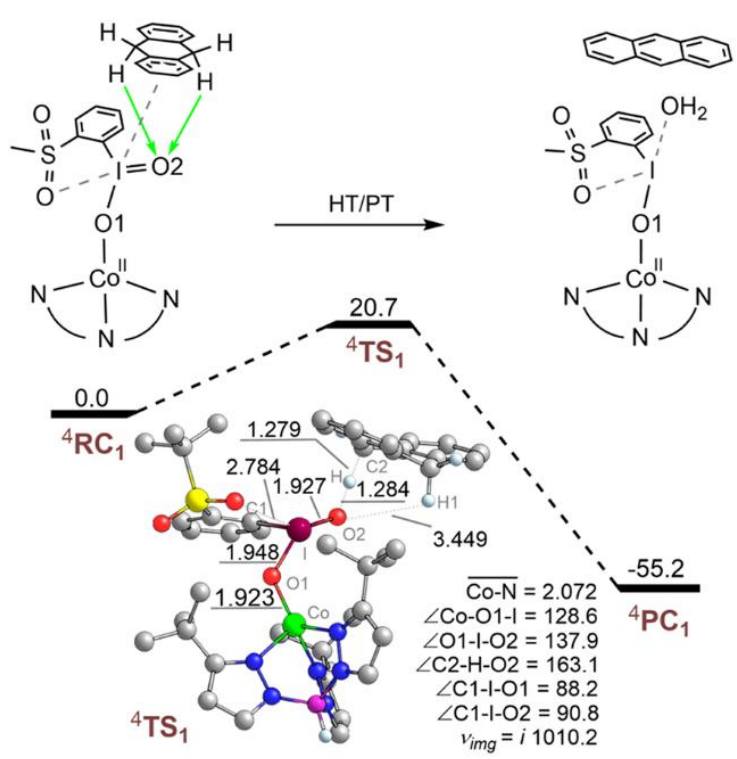

Fig. 4 Energy profile (in $\mathrm{kcal} \mathrm{mol}^{-1}$ ) for anthracene formation in DHA oxidation by 1 via a concerted hydride transfer/proton transfer (HT/PT) mechanism. Energie were calculated at the UB3LYP-D 3 (BJ)/B2//B1+ZPE/B1 level in solvent. Geometric


hydrogen of the H-B moiety and hydrogen of the methylene group in DHA) are imaginary frequency is in $\mathrm{cm}^{-1}$ units. The dotted-lines denote halogen bonding.

non-bonding, bonding ones) of phenyliodine diacetate (PIDA), a well-known molecule having $3 \mathrm{c}-4 \mathrm{e}$ bond (Fig. 3a), with the corresponding MOs of the transition state (Fig. 3b), we can see nearly identical shapes of the MOs. Thus, one $3 c-4 e$ bond is gradually formed during oxygen transfer. The delocalization effect of such bonds makes a difference to the reactivity, by reducing the barrier with ca. $18 \mathrm{kcal} \mathrm{mol}^{-1}$ (the non-3c-4e activation barrier is ca. $38.0 \mathrm{kcal} \mathrm{mol}^{-1}$, shown in Fig. S20, ESI). These interactions mimic the charge-donation effect by fluorinated alcohols on epoxidation reactions that were shown to enhance their reactivities. ${ }^{15}$
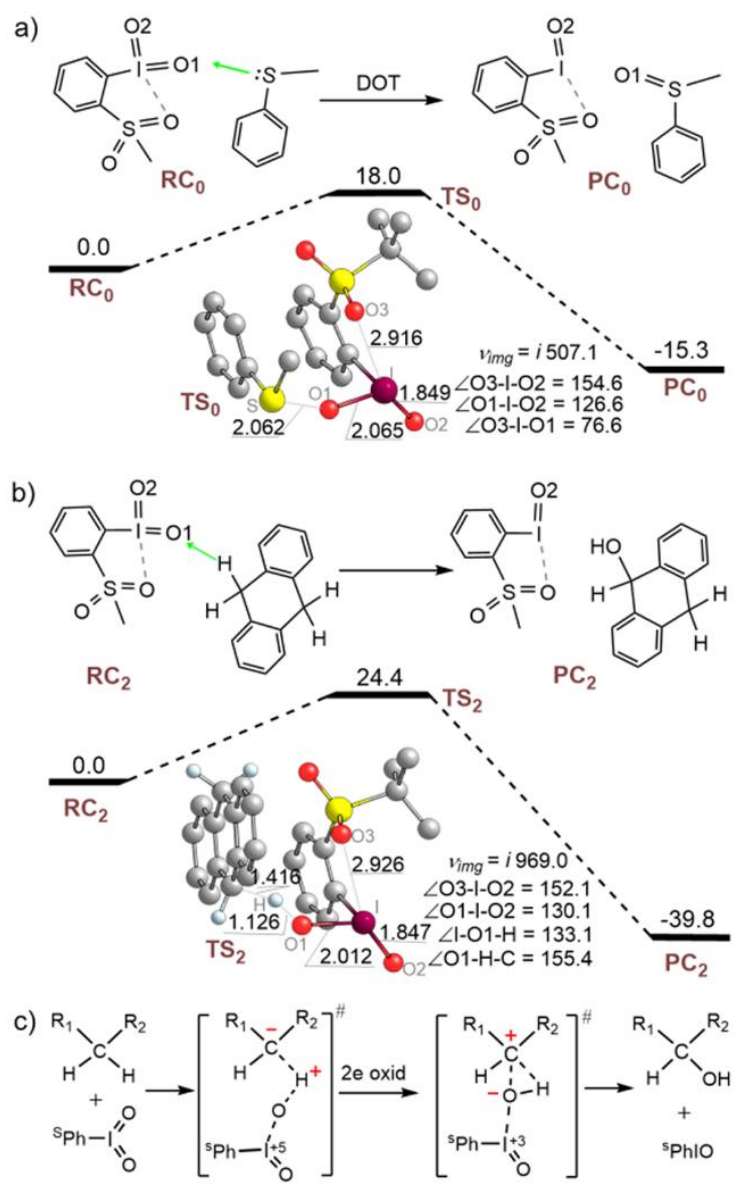

Fig. 5 Energy profiles (in $\mathrm{kcal} \mathrm{mol}^{-1}$ ) for (a) sulfoxidation of thioanisole and (b) hydroxylation of DHA by a ${ }^{\mathrm{P} h \mathrm{O}_{2}}$ monomer with key geometric information of the transition states. Energies were calculated at the UB3LYP-D3(BJ)/B2//B1+ZPE/B level in solvent. Hydrogen atoms (expect hydrogen of the methylene group in the imaginary frequencies are in $\mathrm{cm}^{-1}$ units.

Fig. 4 shows energy profiles and key geometric information of transition states of dehydrogenation of DHA by 1 . The activation energy of the first $\mathrm{C}-\mathrm{H}$ abstraction is $20.7 \mathrm{kcal} \mathrm{mol}^{-1}$, which is much higher than the barrier of DHA oxidation $(9.0 \mathrm{kcal}$ $\mathrm{mol}^{-1}$ ) by a high-valent $\mathrm{Mn}(\mathrm{V})$-oxo complex. ${ }^{16} \mathrm{After}$ the first $\mathrm{C}-\mathrm{H}$ abstraction, a concerted second $\mathrm{C}-\mathrm{H}$ abstraction of the other methylene group occurs and anthracene is formed after such desaturation process. Similar to thioanisole sulfoxidation, the phenyl ring of DHA forms a week XB interaction with the iodine of the Co-iodylarene adduct 1 (at a distance of $3.373 \AA$, see Figure S14 in ESI). The O1-I-O2 angle changes dramatically from $102.9^{\circ}$ in ${ }^{4} \mathrm{RC} 1$ to $137.9^{\circ}$ in ${ }^{4} \mathrm{TS} 1$, forming also an approximate Tshaped $01-I(\mathrm{Ph})-02$ species. Such $\mathrm{O} 1-\mathrm{I}-\mathrm{O} 2$ angle variation keeps rising to the product complex $\left({ }^{4} \mathrm{PC} 1\right)$ state, where the angle is $175.3^{\circ}$. In addition, in the transition states the $\mathrm{C}-\mathrm{H}-\mathrm{O} 1$ angle is $163.1^{\circ} / 164.7^{\circ}$, which is more bent compared to the hydrogen atom abstraction transition states in P450 chemistry. ${ }^{14}$ Surprisingly, there is no spin density on $\mathrm{H}$ and the DHA-H moiety in ${ }^{4}$ TS1 (Fig. S17, ESI), the Mulliken charges on the DHA-H group change from a negative value (ca. -0.17) in the reagent complex to a slightly positive one (ca. 0.14 ) in the ${ }^{4} \mathrm{TS1}$, which means DHA-H is cationic. Unfortunately, we were not able to obtain the reaction intermediate of the first $\mathrm{C}-\mathrm{H}$ bond activation as we 
had in Cho's Mn-PhIO reaction system. ${ }^{17}$ However, in Cho's system, the DHA-H moiety holds similar small positive charge, and the spin is zero in the transition states, similar to the results obtained for Anderson's system. Thus, we can expect that the mechanism of dehydrogenation of DHA by $\mathbf{1}$ is similar to that in Cho's Mn-PhIO reaction system, namely an ionically concerted hydride transfer ${ }^{18-19} /$ proton transfer (HT/PT) process. ${ }^{17}$ The earliest report we could find of hydride attack from DHA is the work by Buchanan where they found that when DHA was solvated in aprotic $\mathrm{SbCl}_{3} / \mathrm{AlCl}_{3}$, a novel hydride abstraction process occurred. ${ }^{20}$ Mizuno reported in 2004 that $\mathrm{Ru}(\mathrm{OH}) \times / \mathrm{Al}_{2} \mathrm{O}_{3}$ could efficiently catalyzes the heterogeneous oxidative dehydrogenation of DHA via a hydride transfer to form a key ruthenium-hydride species. ${ }^{21}$ Hydride transfer has also been extensively found in oxidation of AcrHR (NADH analogues, 10-methyl-9,10-dihydroacridine) with metal-oxo complexes or metal-iodosylarene complexes. ${ }^{22-24}$ Other $\mathrm{C}-\mathrm{H}$ oxidations via the hydride transfer mechanism were also proposed(reactions of $\left[\mathrm{Fe}^{\mathrm{IV}}(\mathrm{O})\left(\mathrm{TPFPP}^{+}\right)\right]^{+}$with 1,3,5cycloheptatriene, ${ }^{25} \mathrm{C}-\mathrm{H}$ amination of xanthene with PhINTs, ${ }^{26}$ methane activation by diatomic $3 \mathrm{~d}$ transition-metal carbides, ${ }^{27}$ etc.).

As a comparison, we performed a mechanistic study on sulfoxidation of thioanisole and dehydrogenation of DHA by an iodylarene monomer ${ }^{\mathrm{S}} \mathrm{PhIO}_{2}$. The two oxygen atoms in ${ }^{\mathrm{S}} \mathrm{PhIO}_{2}$ are inequivalent, i.e., the oxygen without $X B$ interaction is more reactive than the oxygen atom $(\mathrm{O} 2)$ with $\mathrm{XB}$ interaction (Fig. S22 and $\mathrm{S} 25, \mathrm{ESI}$ ), thus in text we only present the more reactive $\mathrm{O1}$ related data (Fig. 5). The activation energies of sulfoxidation of thioanisole and hydroxylation of DHA are $18.0 \mathrm{kcal} \mathrm{mol}^{-1}$ and $24.4 \mathrm{kcal} \mathrm{mol}^{-1}$, which is much higher in energy than those using an iodosylarene monomer (e.g., for sPhIO, barriers of thioanisole oxidation and DHA oxidation are 17.0 and $20.2 \mathrm{kcal}$ $\mathrm{mol}^{-1}$, respectively. See Fig. S32 and S34, ESI) and the metaliodylarene adduct 1 as oxidants. 6,19 In line with the oxidation reactions by 1 , the oxidation by ${ }^{\mathrm{S}} \mathrm{PhIO}_{2}$ is an ionic concerted $2 \mathrm{e}$ oxidation, that is, sulfoxidation of thioanisole by ${ }^{\mathrm{s}} \mathrm{PhIO}_{2}$ is a direct oxygen-atom transfer process and hydroxylation of DHA is an ionically concerted hydride transfer/hydroxyl rebound process (Fig. S28, ESI).

In summary, we present the first theoretical study on the structure-reactivity relationship of metal-iodylarene $\left(\mathrm{M}-\mathrm{PhIO}_{2}\right)$ complexes. We show that the system does not need to form a high-valent $\mathrm{Co}(\mathrm{IV})$-oxo species, but instead the $\mathrm{M}-\mathrm{ArIO}_{2}$ species itself acts as the active oxidant in thioanisole sulfoxidation and $\mathrm{C}-\mathrm{H}$ bond activation of substrates. The computed results presented above demonstrate that the metal-iodylarene (M$\left.\mathrm{PhIO}_{2}\right)$ chemistry is quite different to the metal-iodosylarene (M-PhIO). For $\mathrm{M}-\mathrm{PhIO}_{2}$ complexes two distinct functionalities are identified. Firstly, the iodine(V) atom of $\mathrm{M}-\mathrm{PhIO}_{2}$ acts as a directing group during substrate binding, via halogen bonding interaction to an electron-rich group of the substrates. Secondly, a $3 \mathrm{c}-4 \mathrm{e}$ bond is formed during oxidations, which reduces activation energies through a strong electron delocalization effect. During substrate approaching, such delocalized effect makes the $\mathrm{O}-\mathrm{I}(\mathrm{s} \mathrm{Ph})-\mathrm{O}$ moiety of $\mathrm{M}-\mathrm{PhIO}_{2}$ complexes gradually evolve to a T-shape, which might enhance the selectivity of the $\mathrm{M}-\mathrm{PhIO}_{2}$ complexes.

This work is supported by the National Natural Science Foundation of China (project 21873052), the Natural Science Foundation of Zhejiang Province (project LQ20B030004).

\section{Conflicts of interest}

There are no conflicts to declare.

\section{Notes and references}

1 P. J. Stang and V. V. Zhdankin, Chem. Rev., 1996, 96, 1123 1178.

2 A. Yoshimura and V. V. Zhdankin, Chem. Rev., 2016, 116 3328-3435.

3 J. T. Groves, T. E. Nemo and R. S. Myers, J. Am. Chem. Soc., 1979, 101, 1032.

4 W. Nam and J. S. Valentine, J. Am. Chem. Soc., 1990, 112, 4977.

5 W. Nam, S. W. Jin, M. H. Lim, J. Y. Ryu and C. Kim, Inorg. Chem., 2002, 41, 3647.

6 Y. Kang, X. X. Li, K. B. Cho, W. Sun, C. Xia, W. Nam and Y. Wang, J. Am. Chem. Soc., 2017, 139, 7444.

7 Y. Kang, F. Wang, F. G. C. Reinhard, C. Xia, S. P. de Visser, Y. Wang, ChemistrySelect, 2018, 3, 3208.

8 R. Barret and M. Daudon, Synthetic Commun., 1990, 20 , 1543.

9 I. M. Geraskin, M. W. Luedtke, H. M. Neu, V. N. Nemykin and V. V. Zhdankin, Tetrahedron Lett., 2008, 49, 7410.

10 I. M. Geraskin, O. Pavlova, H. M. Neu, M. S. Yusubov, V. N. Nemykin and V. V. Zhdankin, Adv. Synth. Catal., 2009, 351 733.

11 K. C. Au-Yeung, Y. M. So, G. C. Wang, H. H. Sung, I. D. Williams and W. H. Leung, Dalton Trans., 2016, 45, 5434.

12 E. A. Hill, M. L. Kelty, A. S. Filatov and J. S. Anderson, Chem. Sci., 2018, 9, 4493.

13 C. R. Landis and F. Weinhold, J. Comput. Chem., 2016, 37, 237.

14 F. Ogliaro, N. Harris, S. Cohen, M. Filatov, S. P. de Visser and S. Shaik, J. Am. Chem. Soc., 2000, 122, 8977.

15 S. P. de Visser, J. Kaneti, R. Neumann and S. Shaik, J. Org Chem., 2003, 68, 2903.

16 K. A. Prokop, S. P. de Visser, and D. P. Goldberg, Angew. Chem. Int. Ed., 2010, 49, 5091.

17 D. Sun, X. Chen, L. Gao, Y. Zhao and Y. Wang, Front. Chem. 2020, 8, 744.

18 J.Li, S. Zhou, M. Schlangen, T. Weiske and H. Schwarz, Angew . Chem. Int. Ed., 2016, 55, 13072.

19 S. J. Kim, R. Latifi, H. Y. Kang, W. Nam and S. P. de Visser, Chem. Commun., 2009, 13, 1562.

20 A. C. Buchanan, A. S. Dworkin and G. P. Smith, J. Org.Chem., $1981,46,471$

21 K. Kamata, J. Kasai, K. Yamaguchi and N. Mizuno, Org. Lett., 2004, 6, 3577.

22 A. Gunay and K. H. Theopold, Chem. Rev., 2010, 110, 1060.

23 Y. Han, Y. M. Lee, M. Mariappan, S. Fukuzumi and W. Nam, Chem. Comm.,2010, 46, 8160.

24 T. Devi, Y. M. Lee, S. Fukuzumi and W. Nam, Dalton Trans., 2021, 50, 675

25 F. G. Cantú Reinhard, S. Fornarini, M. E. Crestoni and S. P. de Visser, Eur. J. Inorg. Chem., 2018, 17, 1854.

26 N. P. van Leest, L. Grooten, J. I. van der Vlugt and B. de Bruin, Chem. Eur. J., 2019, 25, 5987

27. C. Y. Geng, T. Weiske, J. L. Li, S. Shaik and H. Schwarz, J. Am. Chem. Soc., 2019, 141, 599. 